Article

\title{
On the Influence of High Turbulence on the Convective Heat Flux on the High-Pressure Turbine Vane LS89
}

\author{
Tânia S. Cação Ferreira ${ }^{1, *}$, Tony Arts ${ }^{1}$ and Emma Croner ${ }^{2}$ \\ 1 Von Karman Institute for Fluid Dynamics, 1640 Sint-Genesius-Rode, Belgium; arts@vki.ac.be \\ 2 Safran Tech, Modelling \& Simulation, 78114 Magny-Les-Hameaux, France; emma.croner@safrangroup.com \\ * Correspondence: cacao@vki.ac.be
}

Received: 12 August 2019; Accepted: 4 November 2019; Published: 8 November 2019

check for updates

\begin{abstract}
High-pressure turbine vanes and blades are subjected to a turbulent combustor flow affecting the heat transfer and boundary layer transition, hence, the temperature distribution. The accurate prediction of the temperature distribution is crucial for a reliable design and cooling implementation. Engine-representative measurements are hence mandatory for improving design tools. Recently, convective heat transfer measurements were conducted on a high-pressure turbine inlet guide vane (VKI LS89 airfoil) in the Isentropic Compression Tube (CT-2) facility at the von Karman Institute. This contribution focuses on the effect of high freestream turbulence generated by a new turbulence grid allowing a range of turbulence intensities in excess of $10 \%$ with representative length scales of the order of 1-2 cm. Three cases with varying turbulence levels are discussed in this paper. The different flow conditions are exit isentropic Mach numbers of 0.70-0.97, Reynolds numbers of $0.53 \times 10^{6}$ and $1.15 \times 10^{6}$ and a constant temperature ratio equal to 1.36 . The heat transfer distributions along the vane suction side indicate a clear link between boundary layer transition and the stream-wise pressure gradients even at high levels of freestream turbulence intensity. Differences are put in evidence in the dynamics of the transition development. Future developments will focus also on the contribution of the other flow parameters under high turbulence. Heat transfer predictions from the boundary layer code TEXSTAN and Reynolds-Averaged Navier-Stokes code elsA (ensemble logiciel pour la simulation en Aérodynamique) are additionally compared to the experiments. Inherent difficulties associated with high turbulence modelling are clear from this early numerical work.
\end{abstract}

Keywords: elevated turbulence intensity; convective heat transfer measurements; boundary layer transition; high-pressure turbines; linear cascade; boundary layer code; Reynolds-Averaged Navier Stokes (RANS)

\section{Introduction}

The design and optimization of gas turbine components is heavily dependent on numerical tools that rely on available experimental databases for validation of their accuracy. Achieving more realistic engine flow conditions is therefore crucial for more and more representative experimental data.

A considerable source of uncertainty and losses in fluid dynamics is due to transition [1], the inception of a turbulent boundary layer, with rising wall shear stress and wall heat flux rates. The high complexity of laminar to turbulent boundary layer transition on a turbine airfoil surface is difficult to characterize due to the flow topology (wall bounded, unsteady, 3D) and non-linear interactions between flow variables [2]. A deeper understanding of this fundamental issue is therefore needed to improve performance predictability and efficiency of gas turbines, leading to safer and greener aviation.

In the framework of high-pressure turbines, the main transition mode occurring on the suction side of a vane or blade is bypass transition. This type of transition occurs due to the perturbed 
freestream environment generated by a combustor chamber where elevated turbulence intensities and length scales are expected. In fact, Laser Doppler anemometry measurements by Goldstein et al. [3] at the exit of a can-type combustor resulted in turbulence levels in the order of $15-20 \%$. Additionally, Van Fossen and Bunker $[4,5]$ also surveyed the outlet flow of a similar combustor measuring very high levels of turbulence intensity (up to $30 \%$ ) and integral length scales $(\sim 3 \mathrm{~cm})$. These elevated levels of combustor generated freestream turbulence are extremely challenging for research turbine inlet guide vane testing facilities.

Several researchers have therefore studied the impact of high freestream, large scale turbulence on the wall heat transfer distribution and boundary layer evolution on high-pressure nozzle vanes. In general, the increase of turbulence intensity leads to higher stagnation heat transfer rates and earlier boundary layer transition; however, there is also a dependency on the integral length scale.

Wang et al. [6] used three turbulence generators to achieve distinct turbulence levels $(3 \%, 8 \%$ and $18 \%)$ and length scales $(0.9,2.6$ and $8 \mathrm{~cm})$. The major effect was to move transition upstream and little or no influence was observed on the laminar boundary layer. Since the increase of turbulence intensity is also followed by an increase of length scale, the latter would contribute to the earlier transition [7] and to lower the stagnation heat transfer $[8,9]$.

Nix et al. [10] developed a turbulence generator reaching 10-12\% turbulence intensity with large scale of $2 \mathrm{~cm}$ where heat transfer results indicate an increase of $8 \%$ for the suction side with respect to the low turbulence case [11]. Further heat transfer measurements by Carullo et al. [12] report an effect of length scale on the stagnation heat transfer: at similar turbulence levels, a higher heating is observed when the integral length scale is smaller (reduced from $24 \mathrm{~mm}$ to $15 \mathrm{~mm}$ ).

A thorough aero-thermal database was developed at the von Karman Institute (VKI) on a high-pressure inlet guide vane [13] which is still today extensively used for numerical studies [14-22]. The major difficulty in these simulations lies in the inlet freestream turbulence generation: the integral length scale size is limited by the available computational resources; lower values lead higher turbulent dissipation and result in a mismatch with the experiments, especially for the stagnation and transition region. Nevertheless, a recent Large Eddy Simulation (LES) work [23] managed to correctly predict the most complex testcase (MUR235) with the experimental turbulence intensity and integral length scale values, raising hope for the future computations of even more complex cases.

In fact, since tested turbulence intensities only ranged from $1 \%$ to $6 \%$, a need emerged for more representative turbulence levels in the turbine testing facility at the VKI. This has led to the design of a novel turbulence grid in order to achieve freestream turbulence intensities higher than 10\% [24].

The aim of the present investigation is hence to study the influence of elevated levels of freestream turbulence on the convective heat transfer and on the behavior of boundary later laminar-to-turbulent transition on the suction side of the VKI LS89 vane. Integral length scales are also provided to help numerical efforts predicting these test cases with more complete inflow conditions.

\section{Experimental Methodology}

\subsection{Facility}

Tests were performed in the CT-2 facility (Figure 1) in the "Jacques Chauvin" laboratory of the VKI. The facility was based on an isentropic compression which allowed simulation of the working conditions of a real engine in terms of temperature ratio and exit isentropic Mach and Reynolds numbers for a short duration of about $0.5 \mathrm{~s}$. The main components of the facility were the high pressurized air supply, the compression tube housing a piston, the test section enclosing the cascade and the discharge tank. More details on the concept and operation principle of this type of test rig can be found in $[25,26]$.

The flow temperature and the exit isentropic Mach and Reynolds numbers were set independently through the pressure level and ratio between the inlet and outlet of the cascade. A sonic throat was placed between the exit of the cascade and the discharge reservoir. In a typical test, the pressure inside 
the discharge reservoir was set close to vacuum to keep the pressure ratio with the test section below the critical value of 0.528 for the whole test duration. The outlet Mach number was therefore also adjusted through the opening area of the sonic throat which allowed it to keep constant despite the finite volume of the discharge reservoir.

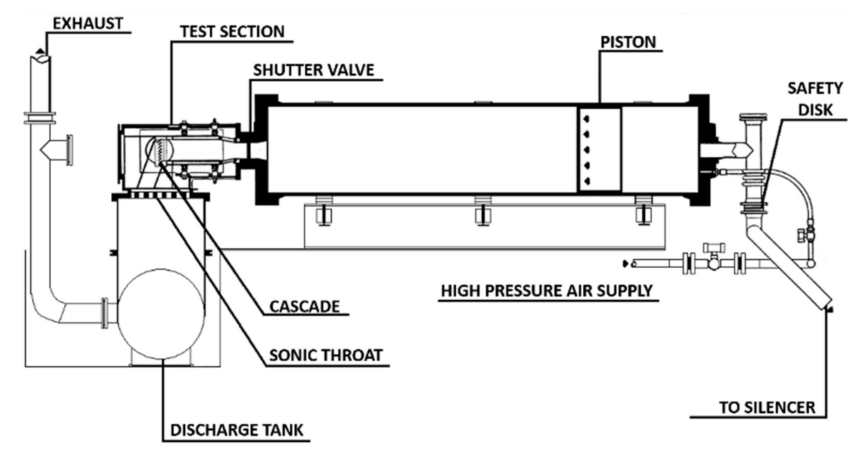

Figure 1. Illustration of the Isentropic Compression Tube (CT-2) facility.

The natural turbulence intensity of the facility was about $0.8 \%$ [27] and it could be increased by placing a turbulence grid in one of the five slots available along the inlet channel of the test section. Depending on the discrete streamwise position of the grid and on the grid itself, five distinct turbulence quantities could be generated at the inlet of the cascade.

\subsection{Turbulence Generator}

Downstream of the compression tube, a shutter valve directed the flow into a straight channel leading to the cascade. The natural turbulence intensity of the facility inside this channel stood at $0.8 \%$, according to the constant temperature hot-wire measurements of Fontaneto [27]. Increasing the turbulence intensity inside the test section was possible by positioning a turbulence grid in one of the five available slots upstream of the vane leading edge plane. These discrete streamwise positions defined the upstream turbulence intensity. Moving the grid closer to the cascade inlet plane provided higher turbulence intensities and smaller integral length scales.

A novel turbulence grid was manufactured to produced higher turbulence levels than the ones used by Arts et al. [13] which stood at a maximum of about 5.3\% [27]. The new turbulence grid generated turbulence intensity levels higher than 10\%; its design and flow field study can be found in [24]. This grid had five bars with a $15 \mathrm{~cm}$ square cross section spaced by $45 \mathrm{~mm}$. The grid could be arranged in two different modes, either with the bar faces orthogonal and parallel to the flow direction (squared configuration; Figure 2, left) or with an angle of $45^{\circ}$ to the flow direction (diamond configuration; Figure 2, right). In the present case, the tests were performed only with the diamond grid configuration due to its higher turbulence generation.

Turbulence quantities were characterized by means of a hot-wire probe operated in a constant temperature mode using a Streamline hardware (90N10 Frame, Dantec Dynamics ${ }^{\circledR}$, Skovlunde, Denmark) and configured through the Dantec Dynamics ${ }^{\circledR}$ StreamWare software (Version 6). A Nuwire vs. $R e_{\text {wire }}$ calibration procedure as depicted by Cukurel et al. [28] was selected due to the varying total temperature between tests. The hot-wire consisted of a platinum-coated tungsten wire of $9 \mu \mathrm{m}$ diameter and $1 \mathrm{~mm}$ active sensor length with an estimated frequency response of $20 \mathrm{kHz}$. The hot-wire signal for each test was acquired for the duration of one second at $100 \mathrm{kHz}$ and low pass filtered at $30 \mathrm{kHz}$ in order to avoid aliasing effects. The uncertainty of the time-resolved velocity measurements in the facility was of $9.85 \%$ for a $95 \%$ confidence interval based on the work of Moffat [29]. The facility only allowed for pointwise measurements at the cascade inlet and therefore the turbulence characteristics were calculated at a discrete pitchwise position. Hence, to verify the uniformity and repeatability of the flow downstream the grid, two distinct pitchwise positions were characterized: behind the wake of one 
bar and in between two bar wakes. The obtained velocities, turbulence intensities and scales as well as pressure drop were very similar. Each turbulence grid configuration and flow condition were repeated at least two times (at different total inlet temperatures) to ensure the uniformity and repeatability of the measurements, given the relatively large size of the bars. The average variation between tests stood at 3\%, indicating a good repeatability between measurements. The average turbulence results provide turbulence intensities between $11 \%$ and $26 \%$. Turbulence integral timescales were computed through the autocorrelation method and the length scale was retrieved using the Taylor hypothesis. The integral timescale was integrated by means of a 4 th order Gaussian fitted autocorrelation curve until the first zero crossing. Integral length scales were estimated to be 1 to $2 \mathrm{~cm}$.
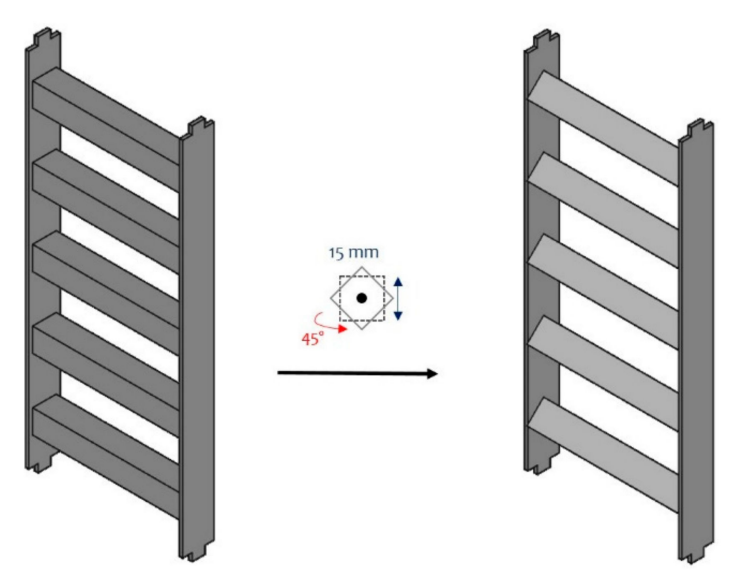

Figure 2. Square (left) and diamond (right) 15mm-bar turbulence grid.

\subsection{Test Section and Model}

The turbine vane model is a well-known inlet nozzle guide vane, the VKI LS89, which established in the 1990s a thorough heat transfer database on the outlet Reynolds $\left(0.5-2.2 \times 10^{6}\right)$ and Mach number (0.7-1.1) and inlet freestream turbulence intensity (1-6\%) [13]. This vane profile was designed for an isentropic outlet Mach number of 0.9 .

The cascade configuration remained the same as in previous work: a linear arrangement of five vanes was placed inside the CT-2 test section, as shown in Figure 3. Only the middle vane was instrumented for the heat transfer measurements; the remaining four were required to ensure periodicity. The cascade inlet and (theoretical) outlet flow angle were fixed at 0 and 75 degrees respectively. The inlet channel had the dimensions of $230 \times 100 \mathrm{~mm}^{2}$, corresponding to exactly four vane passages with a pitch of $57.5 \mathrm{~mm}$ each.

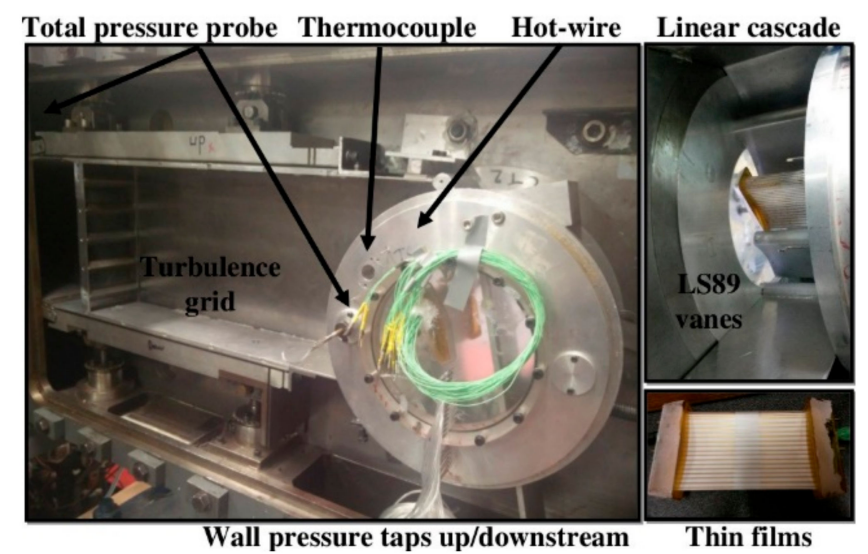

Figure 3. Photograph of the CT-2 test section (left), linear cascade (upper right) and ceramic thin film instrumented central vane (bottom right). 


\subsection{Pressure Measurements}

The pressure acquisition was of importance to establish the operating flow conditions of each test through to the compression in the tube and expansion across the cascade.

The pressure inside the compression tube was acquired by a pitot probe connected to a variable reluctance differential pressure transducer (Validyne ${ }^{\circledR}$, Northridge, CA, USA). The cascade outlet static pressure distribution was measured by a miniature pressure scanner (Scanivalve ${ }^{\circledR}, \mathrm{ZOC} 33 / 64 \mathrm{PX} \pm 1$ bar, Liberty Lake, WA, USA); twenty-two wall taps were individually connected to the scanner. The taps were placed at $43 \%$ axial chord downstream of the trailing edge plane and covered two pitches. National Instruments semiconductor differential transducers were used for the remaining pressures: total inlet pressure was also measured using a pitot probe, static inlet pressure was an average of two wall taps and static pressure in the discharge tank was linked through a pneumatic line.

The isentropic exit Mach number was here defined based on the measured cascade inlet total and outlet static pressure:

$$
M_{i s, \text { out }}=\sqrt{\left({\frac{P_{\text {out }}}{P_{0, \text { in }}}}^{\frac{1-\gamma}{\gamma}}-1\right) \frac{2}{\gamma-1}}
$$

where $\gamma$ is the specific heat ratio of air, equal to 1.4 for the range of tested flow temperatures.

\subsection{Gas Temperature Measurement}

The inlet total temperature of the flow was acquired by a $25 \mu \mathrm{m}$ type $\mathrm{K}$ bare thermocouple. The thermocouple was placed one and a half axial chord upstream of the cascade leading edge place. Given that the thermocouple wires were normal to the flow, a recovery factor of 0.68 [30] was applied to the measured total temperature. The exit isentropic Reynolds number was based on the vane chord $C(C=$ $67.647 \mathrm{~mm}$ ) and was computed due to the isentropic expansion assumption through the cascade and temperature and pressure measurements:

$$
R e_{i s, \text { out }}=\frac{\rho_{i s, \text { out }} U_{i s, \text { out }} C}{\mu_{i s, \text { out }}}
$$

\subsection{Wall Temperature Measurement}

The central vane was instrumented with thin films for the wall temperature and heat transfer measurements. The vane was made of Macor ${ }^{\circledR}$ glass ceramic, a good thermal and electric insulator, whose thermal proprieties are written in Table 1; its suction side was covered with twenty-seven platinum thin films ( $\sim .5 \mu \mathrm{m}$ of thickness). The manufacturing characteristics of these thin films can be found in [31]. The insulating proprieties of the substrate drive the semi-infinite assumption which, considering the negligible thin film thickness and short duration of the test, implies that any variation of the thin film temperature was not influenced by the substrate [32,33]. The wall temperature measurements were thus possible due to the linear variation of resistance with temperature:

$$
R=R_{0} \cdot\left[1+\alpha_{R}\left(T-T_{0}\right)\right]
$$

where $R_{0}$ is the thin film resistance at a temperature $T_{0}$ and $\alpha_{R}$ is the temperature coefficient of resistance obtained in an oil bath calibration. Since the thin films were integrated in a constant current Wheatstone bridge, Ohm's law implies a linear evolution of voltage with resistance which leads to:

$$
V=V_{0} \cdot\left[1+\alpha_{R}\left(T-T_{0}\right)\right]
$$

where $V_{0}$ is the initial thin film voltage, at temperature $T_{0}$. The wall temperature was then directly retrieved from the measured voltage signal. 
Table 1. Vane substrate Macor ${ }^{\circledR}$ material thermal properties.

\begin{tabular}{cc}
\hline Volumetric mass density, $\rho\left(\mathrm{kg} / \mathrm{m}^{3}\right)$ & 2520 \\
Specific heat, $c(\mathrm{~J} / \mathrm{kg} \mathrm{K})$ & 752 \\
Thermal conductivity, $k(\mathrm{~W} / \mathrm{m} \cdot \mathrm{K})$ & 1.672 \\
\hline
\end{tabular}

The temperature ratio $\left(T_{g} / T_{w}\right)$ defined in this paper corresponded therefore to the ratio between the gas, i.e., the inlet total, temperature $\left(T_{0, i n}=T_{g}\right)$ and the initial wall temperature $\left(T_{w}\right)$.

\subsection{Wall Heat Flux Measurement}

The heat flux was derived from the thin film thermometry measurements by means of electrical circuits. These circuits were based on the electrical analogy of heat conduction in a semi-infinite body to a long series of resistances and capacitances where the voltage and current behavior was similar to the one of the temperature and current $[34,35]$. This is best illustrated through their governing equations: it can be seen that the Fourier law and the unsteady $1 \mathrm{D}$ heat conduction equation were respectively analogous to Ohm's law (Equation (5)) and to the transmission line circuit equation (Equation (6)).

$$
\begin{gathered}
\dot{q}=-k \frac{\partial T}{\partial x} \Longleftrightarrow i=-\frac{1}{R} \frac{\partial V}{\partial x} \\
\frac{\partial^{2} T}{\partial x^{2}}=-\frac{\rho c}{k} \frac{\partial T}{\partial t} \Longleftrightarrow \frac{\partial^{2} V}{\partial x^{2}}=-R C \frac{\partial V}{\partial t}
\end{gathered}
$$

The heat flux can be obtained by solving the second order partial differential equation through the Laplace transform. In terms of the electric analogy, the solution can be written as [36]:

$$
\dot{q}_{w}=\frac{V_{o u t}}{V_{0}} \frac{\sqrt{\rho c k}}{\alpha_{R}} \frac{A^{*}}{\beta}
$$

where $V_{\text {out }}$ is the thin film Wheatstone bridge output voltage, $\mathrm{V}_{0}$ is the thin film voltage, $\sqrt{\rho c k}$ is the substrate thermal product, $\alpha_{R}$ is the thin film temperature coefficient of resistance and $A / \beta^{*}$ is the analog circuit calibration coefficient.

\subsection{Data Acquisition}

All pressure, temperature and heat flux measurements were acquired using the TEAM256 software (Version 7.20, LDS Nicolet ${ }^{\circledR}$, Middleton, WI, USA) controlling a 64-channel BE256 data acquisition system (Bakker Electronics ${ }^{\circledR}$, Dongen, Netherlands')except for the outlet pitch-wise static pressure and the hot-wire measurements. The former signals were recorded for a duration of $1.25 \mathrm{sec}$ at a frequency of $50 \mathrm{kHz}$. Additionally, the analog circuits signals were amplified $(\times 100)$ and low pass filtered at $12 \mathrm{kHz}$ before recording. Twenty-two outlet static pressure signals covering two pitches were acquired by means of a Scanivalve ${ }^{\circledR}$ pressure scanner. One-thousand samples were collected at a frequency of $312.5 \mathrm{~Hz}$.

The hot-wire is operated using the Dantec Dynamics ${ }^{\circledR}$ Streamline hardware and configured through the Dantec Dynamics ${ }^{\circledR}$ StreamWare software. The signal for each test was acquired for the duration of one second at $100 \mathrm{kHz}$ and low pass filtered at $30 \mathrm{kHz}$ in order to avoid aliasing effects.

\subsection{Uncertainty Analysis}

The uncertainty analysis is based on the work of Moffat [29] within a confidence interval of $95 \%$, Table 2. The uncertainties were estimated from both the calibration curves and from the measurements using the error propagation method. The uncertainties on the outlet isentropic Mach and Reynolds numbers were, respectively, $2.3 \%$ and $4.1 \%$ while for the temperature ratio it was of the order of $0.8 \%$. 
The convective heat transfer results had an associated uncertainty of $9.5 \%$. The isentropic inlet velocity from which the turbulence intensities were computed had an uncertainty of $9.9 \%$.

Table 2. Uncertainties within a 95\% confidence interval.

\begin{tabular}{cccccc}
\hline \multirow{2}{*}{ Uncertainty [\%] } & $\boldsymbol{T}_{g} / \boldsymbol{T}_{w}$ & $\boldsymbol{M}_{\text {is, out }}$ & $\boldsymbol{R} \boldsymbol{e}_{\text {is,out }}$ & $\boldsymbol{V}_{\text {in }}$ & $\boldsymbol{h}$ \\
\cline { 2 - 6 } & 0.8 & 2.3 & 4.1 & 9.9 & 9.5 \\
\hline
\end{tabular}

\section{Heat Transfer Measurements: Results and Discussion}

Assessment of the effect of turbulence intensity was possible by changing the position of the turbulence grid in the test section's inlet channel of the facility. The effects of turbulence intensity were analyzed through the heat transfer coefficient distribution along the suction side of the vane. The link with the boundary layer status was complemented with a numerical prediction of the Mach number distribution.

The thermal boundary layer evolution on the vane suction side can be illustrated by its heat transfer coefficient distribution, defined in the present work as:

$$
h=\frac{\dot{q}_{w}}{T_{0, \text { in }}-T_{w, \text { initial }}}
$$

Convective heat transfer measurements reveal a stagnation region characterized by high heat flux due to hot flow impinging on a still developing thin laminar boundary layer. Because of its nature, the latter acted as an insulating layer and the heat transfer decreased continuously downstream of the stagnation point. A further variation in heat transfer would be due to a change in acceleration, separation bubbles, shocks or transition (which can be also triggered by the former factors).

\subsection{Comparison with Arts et al.}

The first step of this work was to compare the heat transfer behavior from the database of [13] with the results from the new grid. In the former work, a turbulence grid of $3 \mathrm{~mm}$ cylindrical bars was used and the maximum turbulence intensity level achieved in the facility was of 5.3\%, according to measurements by Fontaneto [27].

Given the significant literature dedicated to predicting the heat transfer distribution of MUR235 (e.g. [15-22]), this test has been selected to be compared with the new result: TUR062. The heat transfer distributions are shown together with a Mach number prediction for $M_{i s, o u t}=0.93$ in Figure 4 .

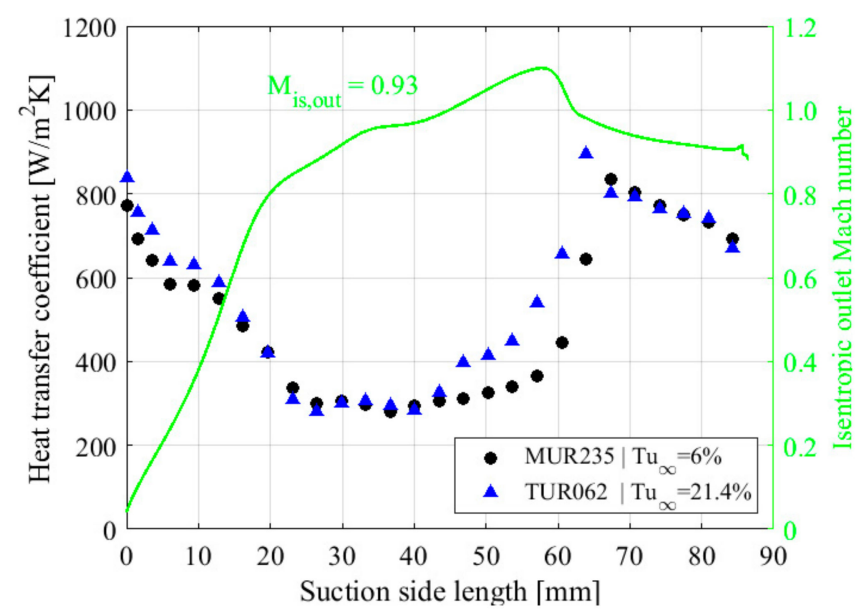

Figure 4. Heat transfer coefficient of MUR235 [13] and TUR062 with a Mach number distribution prediction for $M_{i s, \text { out }}=0.93\left(R e_{i s, \text { out }}=1.02 \times 10^{6}\right)$ along the suction side. 
The flow conditions for both tests are described in Table 3. The turbulent integral length scale for the same turbulence grid configuration as in MUR235 was experimentally measured to be around $7.5 \mathrm{~mm}$ [27]. Regarding the stagnation region, the effect of the turbulence intensity was to increase the heat transfer by $9 \%$, which then converge to similar heat transfer levels as MUR235 in the laminar region. The heat transfer coefficient increase was at $s=40 \mathrm{~mm}$, after the plateau observed on the isentropic Mach number distribution. LES results by [17] put into evidence the presence of acoustic waves at this exact position. For test case MUR235, these disturbances were damped, and transition developed more energetically due to the adverse pressure gradient starting from $\mathrm{s}=60 \mathrm{~mm}$ where a shock was expected to occur $[17,37]$. However, for the higher turbulence case, we observed the clear evolution of transition starting from $s=40 \mathrm{~mm}$, even if it was slowed due to the favorable pressure gradient. From the time-resolved heat flux signal, high amplitude fluctuations indicate that the boundary layer was already destabilized since the change in acceleration at about $s=20 \mathrm{~mm}$.

Table 3. Flow conditions of MUR235 and TUR062.

\begin{tabular}{ccccc}
\hline Test & $\boldsymbol{T} \boldsymbol{u}_{\infty}[\%]$ & $\boldsymbol{M}_{\text {is,out }}$ & $\boldsymbol{R} \boldsymbol{e}_{\text {is,out }}$ & $\boldsymbol{T}_{g} / \boldsymbol{T}_{\boldsymbol{w}}$ \\
\hline MUR235 & 6 & 0.93 & $1.15 \times 10^{6}$ & 1.37 \\
TUR062 & 21.4 & 0.93 & $1.16 \times 10^{6}$ & 1.35 \\
\hline
\end{tabular}

\subsection{Experimental Results Analysis}

Heat transfer distributions along the suction side of the vane are displayed to characterize the influence of freestream turbulence. Numerical predictions of the suction side Mach number distributions are also included in the figures. Three distinct levels of turbulence intensity are put side-by-side and compared. Three test cases were selected from the experimental campaign results and their flow conditions are summarized in Table 4.

Table 4. Flow conditions of test cases.

\begin{tabular}{cccccc}
\hline \multirow{2}{*}{ Case } & $\boldsymbol{M}_{\text {is,out }}$ & $\boldsymbol{R} \boldsymbol{e}_{\text {is,out }}$ & $\boldsymbol{T}_{\boldsymbol{g}} / \boldsymbol{T}_{\boldsymbol{w}}$ & $\mathbf{T} \boldsymbol{u}_{\infty}$ & $\boldsymbol{\Lambda}_{\boldsymbol{x}}$ \\
\cline { 2 - 6 } & $\mathbf{( - )}$ & $\mathbf{( \times \mathbf { 1 0 } ^ { \mathbf { 6 } } )}$ & $\mathbf{( - )}$ & $\mathbf{( \% )}$ & $\mathbf{( m m )}$ \\
\hline $\mathrm{A}$ & 0.70 & 1.15 & 1.36 & $13-26$ & $13-23$ \\
$\mathrm{~B}$ & 0.97 & 0.53 & 1.35 & $13-22$ & $14-17$ \\
$\mathrm{C}$ & 0.92 & 1.15 & 1.36 & $11-21$ & $15-21$ \\
\hline
\end{tabular}

\subsubsection{Case A-Subsonic and High Reynolds}

The first case study is a fully subsonic experiment $\left(M_{i s, \text { out }}=0.70, R e_{i s, \text { out }}=1.15 \times 10^{6}\right)$; the time-averaged suction side heat transfer coefficient distribution is shown in Figure 5. Each turbulence intensity increment of about $6 \%$ allows the advancement of the transition region by one measuring position, corresponding to approximately $3 \mathrm{~mm}$ ( $3.5 \%$ of the suction side length).

An increase of the stagnation heat transfer coefficient is also present, but it is not as clear for the two lower turbulence intensities. However, looking at the minimum and maximum heat transfer coefficient values presented in Figure 6, a difference of about $100 \mathrm{~W} / \mathrm{m}^{2} \mathrm{~K}(\sim 12.5 \%)$ is observed on the maximum heat transfer values between tests. These values correspond to the maximum heat transfer fluctuations due to the increase of turbulence intensity. Regarding the minimum or base heat transfer coefficient, it remains the same except for the lower turbulence intensity case after $s=50 \mathrm{~mm}$. A justification for this can lie on their individual boundary layer evolution: around this position, the highest turbulence intensity cases are almost turbulent whereas the lowest appears to be still half-way through transition (Figure 5). 


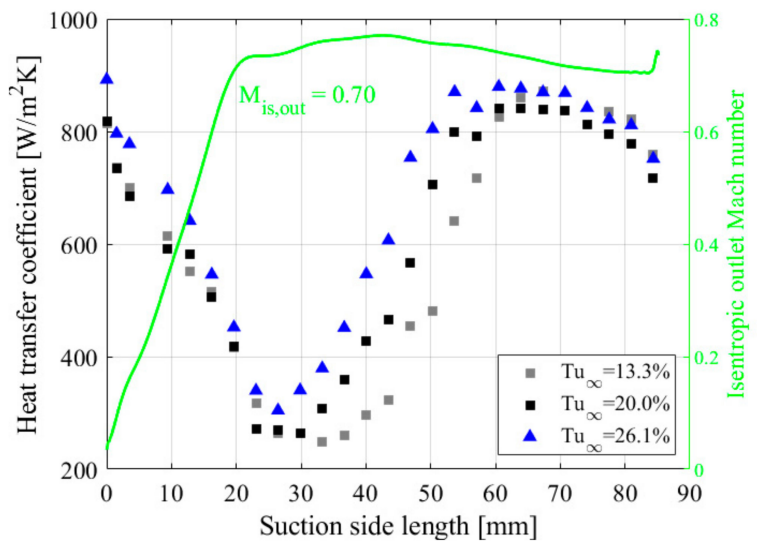

Figure 5. Suction side mean heat transfer coefficient distribution (Case A: $M_{i s, \text { out }}=0.70, R e_{i s, \text { out }}=1.15$ $\left.\times 10^{6}, T_{g} / T_{w}=1.36\right)$ and Mach number distribution prediction for $M_{i s, \text { out }}=0.70\left(R e_{i s, \text { out }}=1.15 \times 10^{6}\right)$.

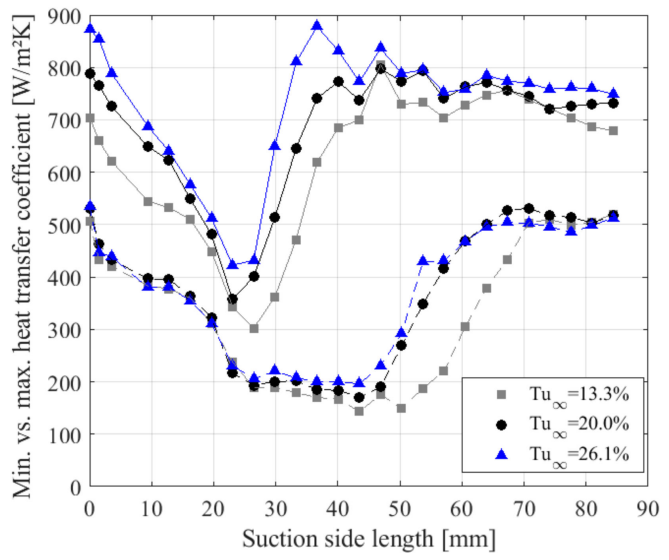

Figure 6. Suction side maximum (solid trace) and minimum (dashed trace) heat transfer coefficient distribution (Case A: $M_{i s, o u t}=0.70, R e_{i s, o u t}=1.15 \times 10^{6}, T_{g} / T_{w}=1.36$ ).

If one compares the averaged values of heat transfer to their maximum and minimum, it appears not to add up to the same result. However, this is solely due to the post-processing: a typical time-series of a single-position wall heat flux as a function of the time-series of the wall temperature provides the wall heat flux temperature series present in Figure 7.

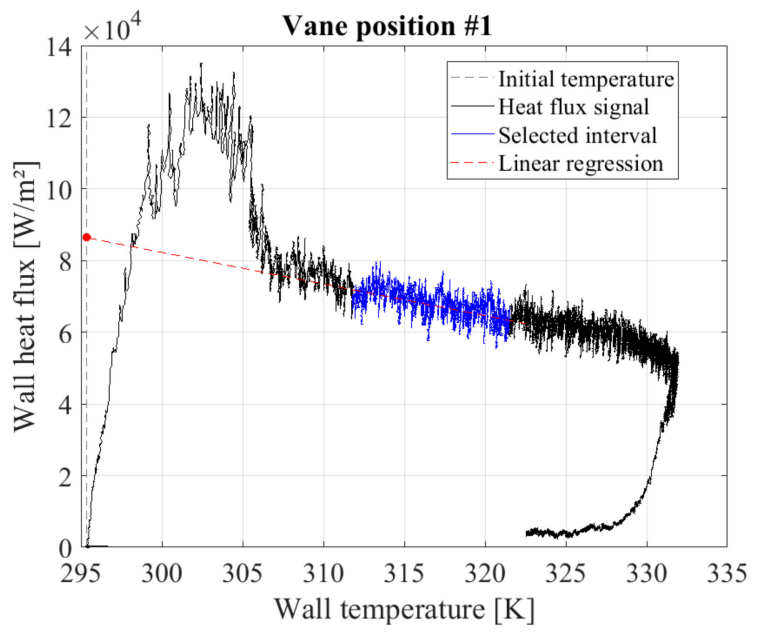

Figure 7. Wall heat flux temperature-series at $s=0 \mathrm{~mm}$ : post-processing the averaged value (Case A: $\left.M_{\text {is,out }}=0.70, R e_{i s, \text { out }}=1.15 \times 10^{6}, \mathrm{~T}_{g} / T_{w}=1.36\right)$. 
A linear regression on a selected interval allows to retrieve the original heat flux value given by the isentropic compression for isothermal and uniform wall conditions [38]. Therefore, this means that a heat transfer value cannot be compared in absolute value to its fluctuations, which was not the purpose of the previous statements.

\subsubsection{Case B-Transonic and Low Reynolds}

Heat transfer measurements for a transonic Mach number distribution at a lower outlet Reynolds number $\left(M_{i s, \text { out }}=0.97, R e_{i s, \text { out }}=0.53 \times 10^{6}\right)$ result in the rather fixed profiles presented in Figure 8 . The velocity distribution, expected to be similar to MUR47 in Arts et al. [13] and to the one shown in this paper (Figure 4), should have the same variations in acceleration around $s=20 \mathrm{~mm}$ and $s=40 \mathrm{~mm}$ followed by a steep deceleration at $s=60 \mathrm{~mm}$. From this position, a shock is expected based on previous flow visualizations by Arts et al. [10] at $M_{i s, \text { out }}=1.03$ and $R e_{i s, \text { out }}=10^{6}$.

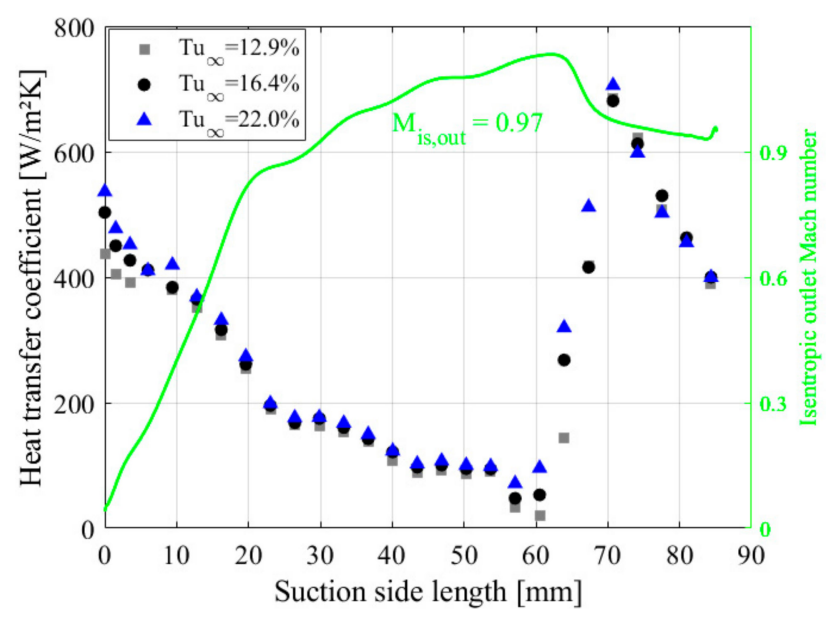

Figure 8. Suction side mean heat transfer coefficient distribution (Case B: $M_{\text {is,out }}=0.97, R e_{i s, o u t}=0.53 \times$ $\left.10^{6}, T_{g} / T_{w}=1.35\right)$ and Mach number distribution prediction for $M_{i s, \text { out }}=0.97\left(\operatorname{Re}_{i s, \text { out }}=0.53 \times 10^{6}\right)$.

Indeed, the above-mentioned velocity variations are clearly reflected in the evolution of the heat transfer slopes. These indicate a laminar boundary layer up to $s=55 \mathrm{~mm}$. An ensuing low heating region between $s=55-60 \mathrm{~mm}$ implies the presence of a laminar separation bubble. Its formation is likely due to being in a region with a strong deceleration/shock. Transition is therefore rapidly driven by the shock, within a small spatial domain between $\mathrm{s}=60-70 \mathrm{~mm}$ where no other effect of turbulence intensity is perceivable.

Regarding the differences in heating, they are present on the stagnation region, with an increase in mean heat transfer of about $16 \%$, and on the separation bubble, where the turbulence appears to reduce the size of the bubble. The latter can be further illustrated through the root-mean-square distribution of the heat transfer coefficient on Figure 9. While the highest freestream turbulence cases present a continuous evolution into the RMS peak, the $T u_{\infty}=12.9 \%$ case shows very small heat flux fluctuations up to this point.

Indeed, the reduction of the bubble size has been reported by Castro and Haque [39] due to the higher entrainment rates resulting from increased freestream turbulence. Additionally, research by Isomoto and Honami [40] on the reattachment over a backward facing step indicates that the increase of the turbulence level near the wall at the separation point leads to a shorter reattachment length. 


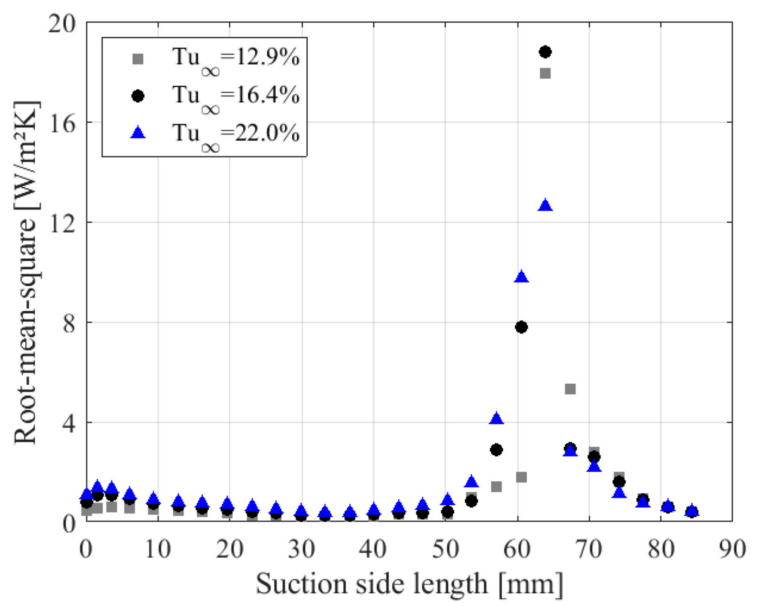

Figure 9. Suction side root-mean-square distribution (Case B: $M_{i s, o u t}=0.97, R e_{i s, o u t}=0.53 \times 10^{6}$, $\left.T_{g} / T_{w}=1.35\right)$.

\subsubsection{Case C—Transonic and High Reynolds}

For a higher Reynolds number and a slightly lower Mach number distribution, still transonic $\left(M_{i s, \text { out }}=0.92, R e_{i s, \text { out }}=1.02 \times 10^{6}\right)$, the boundary layer status is more varied (Figure 10). A Mach number prediction is additionally presented: the velocity distribution displays variations in acceleration around $s=20$ and $40 \mathrm{~mm}$ and a diffusion region where a shock is expected around $s=60 \mathrm{~mm}$. These are reflected as heat transfer variations and, due to the increase in Reynolds number, a separation bubble is no longer present. After the shock, the boundary layer is rapidly evolving to the fully turbulent status; however, its behavior before the shock is distinct. The increase of heat transfer for the highest turbulence case takes place earlier. The heat transfer coefficient starts to increase after the velocity plateau at $s=40 \mathrm{~mm}$. A subsequent favorable pressure gradient, however, is delaying a strong development of the boundary layer transition. As it had been pointed out by Chong and Zhong [41], acceleration acts to inhibit the turbulent spots heat transfer, slowing its spanwise growth during the transition process in the thermal boundary layer.

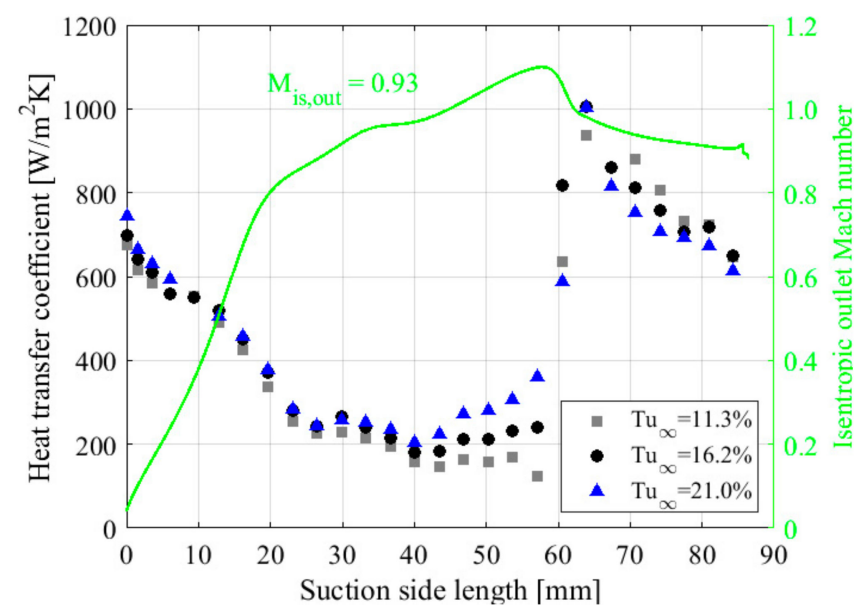

Figure 10. Suction side mean heat transfer coefficient distribution (Case $C: M_{i s, \text { out }}=0.92, R e_{i s, \text { out }}=1.02$ $\left.\times 10^{6}, T_{g} / T_{w}=1.36\right)$ and Mach number prediction $\left(M_{i s, \text { out }}=0.93, R e_{i s, \text { out }}=1.02 \times 10^{6}\right)$.

Another interesting observation is the difference in the turbulent heat transfer, higher for the lower turbulence intensity cases. Since the lower turbulence case is triggered almost instantaneously by the shock $(s=60 \mathrm{~mm})$, it has a shorter streamwise transition development. This results in a smaller boundary layer thickness compared to the other cases where the boundary layer transition starts 
around $s=40 \mathrm{~mm}$. A thinner turbulent boundary layer would thus lead to a higher heat transfer from the flow to the wall.

\subsection{Stagnation Region Heat Transfer}

The present heat transfer measurements are compared to a correlation from Van Fossen et al. [42] for the stagnation region of elliptical leading edges. The turbulence intensity $T u_{\infty}$, integral length scale $\Lambda_{x}$, the inlet Reynolds number based on the leading-edge diameter $R e_{D, \text { in }}$ and the leading-edge diameter itself $D(D=8.25 \mathrm{~mm})$ are considered in the correlation defined as:

$$
\frac{F r_{t}}{F r_{l}}=0.00851 \sqrt{T u_{\infty} R e_{d, i n}^{0.8}{\frac{\Lambda_{x}}{D}}^{-0.574}}+1
$$

The Frossling number is but a normalization of the Nusselt number by $\sqrt{ } \operatorname{Re}$ given their proportionality in the laminar boundary layer. The turbulent Frossling number $F r_{t}$ of the present experimental data is obtained through:

$$
F r_{t}=N u \frac{D / C}{\sqrt{\operatorname{Re}_{D, i n}}}
$$

After the heat transfer results were converted in Nusselt number:

$$
N u=\frac{h \cdot C}{k}
$$

where $k$ is the air thermal conductivity and $C$ is the vane chord. The inlet Mach number was in the order of 0.17 .

The laminar Frossling number $\mathrm{Fr}_{l}$ depends on the velocity gradient and is given as a function of the body shape. Since the leading edge of the VKI LS89 vane can be approximated to a 1.5:1 aspect ratio ellipse, the correspondent numerical solution for the laminar Frossling number is $F r_{l}=0.870$ [42].

A comparison between the correlation and the present experimental results is presented in Figure 11. Even if the correlation itself displayed only $4 \%$ of data scatter, stagnation heat transfer data from other authors was fitted into this correlation to within $10 \%$. Therefore, the current results are within the model's expected uncertainty except for the lowest turbulence and Reynolds number case (Case $\left.\mathrm{B}, T u_{\infty}=13 \%\right)$. This might lie on the uncertainty of the heat transfer measurements since a difference in turbulence intensity or scale would still place the point below the uncertainty band.

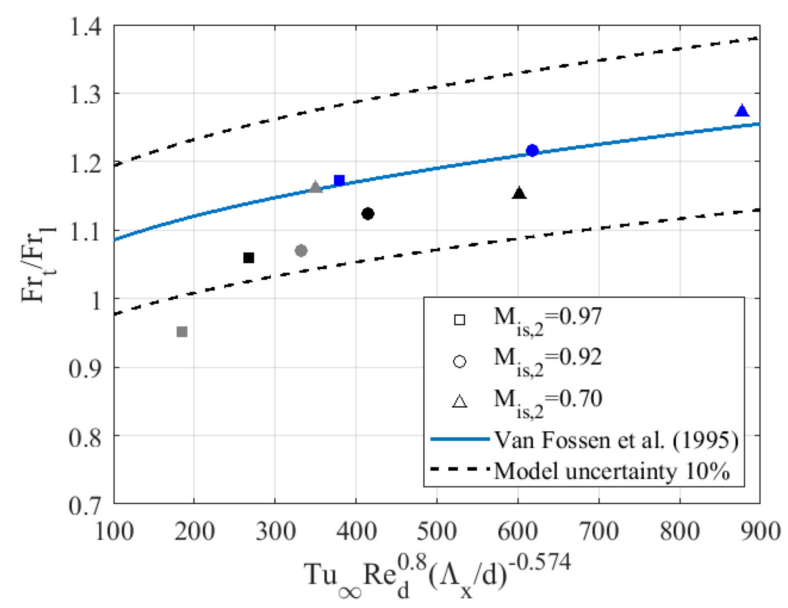

Figure 11. Van Fossen et al. [35] correlation vs. present experimental data: low $T u_{\infty}$ (grey), middle $T u_{\infty}$ (black), high $T u_{\infty}$ (blue). 
The correlation considers also the integral length scale since it also affects the stagnation heat transfer. It has been shown that for the same turbulence intensity, smaller length scales will lead to higher levels of heat transfer [8].

Hence, considering that in the present case the lowest turbulence intensity is obtained by placing the grid the furthest away from the cascade inlet section, it results in larger integral length scales since they grow with the streamwise distance [42]. Therefore, maximum stagnation heat transfer levels are still expected for the highest turbulence intensity cases since the produced length scales are the smallest.

In sum, the present freestream turbulence is found to have a moderate effect in increasing the stagnation heat transfer. This is also seen in Wang et al. [6] for turbulence intensity levels between 3\% and $18 \%$, where the major effect is to trigger earlier the onset of boundary layer transition, as seen in the present work in the absence of strong pressure gradients (Case A).

\section{Heat Transfer Numerical Predictions: Results and Discussion}

Two distinct numerical approaches were used for a comparison with experimental heat transfer results at elevated turbulence intensities. These models are not expected to correctly predict the transition behavior but rather to compare to the laminar (non-stagnation) and turbulent region and to show the extent of their limitation at elevated turbulences. Accurate flow predictions for these cases would require the use of more complex numerical approaches like LES or Direct Numerical Simulation (DNS).

\subsection{Boundary Layer Code: TEXSTAN}

The academic boundary layer code TEXSTAN [43] solves the convective transport of heat, momentum and mass transfer through the 2D parabolic boundary layer equations. Abu-Ghannam and Shaw's (AG-S) mixing length model is presently used with a constant turbulent Prandtl number. Further details on the initial/boundary conditions can be found in previous work [37].

\subsection{Reynolds-Averaged Navier-Stokes Code: elsA}

Steady bidimensional (2D) Reynolds-Averaged Navier-Stokes (RANS) simulations have been run with the ONERA code elsA [44,45], based on cell-centered finite volume discretization. Turbulence closure is ensured by Menter's two-equation $\kappa-\omega$ model in its shear-stress transport (SST) version [46]. Additionally, laminar-to-turbulent transition is modelled thanks to Langtry and Menter's $\gamma-R e_{\theta t}$ model [47], finally resulting in a four-equation modelling.

\subsection{Case A-Subsonic and High Reynolds}

The heat transfer prediction of Case A using TEXSTAN and elsA is shown in Figure 12. Since the first approach does not account for the stagnation region freestream turbulence effects, it results in an underprediction of this region and the laminar heat transfer. Nevertheless, the same mixing length model provided a correct prediction of the stagnation and laminar heat transfer for test cases without the turbulence grid [30]. The elsA simulation of the low turbulence intensity case gives a closer prediction to the experiments; however, the highest turbulence results in an overprediction of the stagnation/laminar heat transfer. Both models, given their use of AG-S correlations, provide a similar transition region, which is earlier and shorter than seen in the experiments. Freestream turbulence above $20 \%$ does not lead however to further hasten the onset of transition. This increase does not affect the correlations due to the correlation formulation: the transition onset momentum thickness Reynolds number is asymptotically approaching the minimum of 163 established in AG-S's correlation. It is clear that the use of this correlation is not appropriate for such high levels of turbulence intensity. 


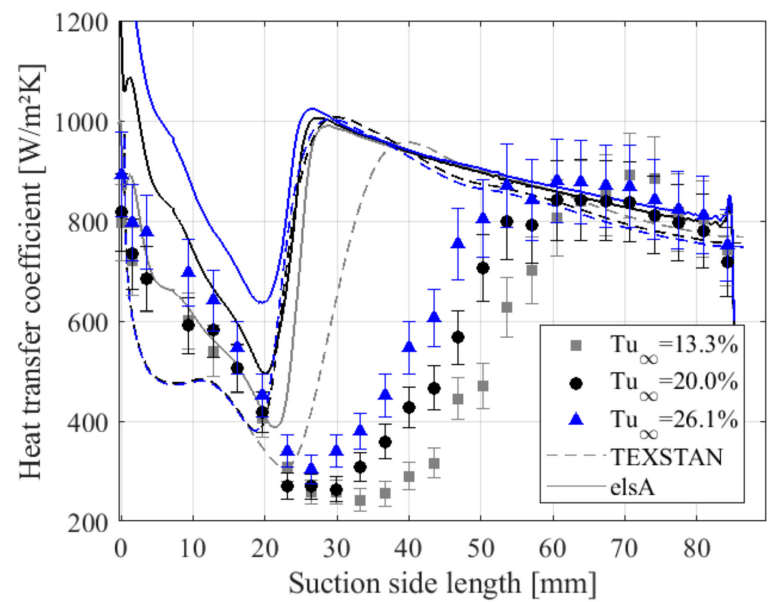

Figure 12. Suction side mean heat transfer coefficient distribution and TEXSTAN and elsA predictions (Case A: $\left.M_{i s, o u t}=0.70, R e_{i s, o u t}=1.15 \times 10^{6}, T_{g} / T_{w}=1.36\right)$.

Nevertheless, heating on the turbulent boundary layer is within the experiments' uncertainty, yielding a good matching from $\mathrm{s}=50-60 \mathrm{~mm}$ to the trailing edge.

\subsection{Case B-Transonic and Low Reynolds}

Figure 13 shows the numerical heat transfer predictions for Case B. TEXSTAN's stagnation region does not fall short from the measurements and the laminar part comes close to the experiments. Transition prediction is however, anticipated, as in elsA's simulation. The latter provides a good laminar prediction even for the maximum $T u_{\infty}=22.0 \%$ and a later transition onset. The turbulent region is only matching towards the trailing edge: transition in the experiments is leading to much higher heating, most likely due to the shock.

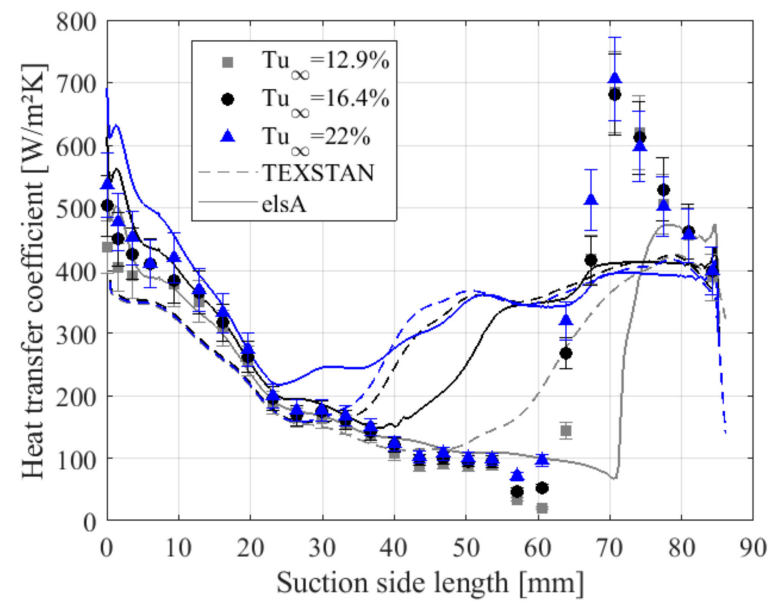

Figure 13. Suction side mean heat transfer coefficient distribution and TEXSTAN and elsA predictions (Case B: $\left.M_{i s, o u t}=0.97, R e_{i s, o u t}=0.53 \times 10^{6}, T_{g} / T_{w}=1.35\right)$.

\subsection{Case C-Transonic and High Reynolds}

In Case C, presented in Figure 14, the mixing length model predicts lower heat transfer rates at the stagnation region as expected, but from $s=20 \mathrm{~mm}$ it converges to the laminar values as the previous cases. The RANS code provides again a good estimation of the stagnation and early laminar heat transfer for the lowest turbulence case; however, higher values lead to an overprediction of these regions. Transition onset is, once more, predicted before the experiments. 


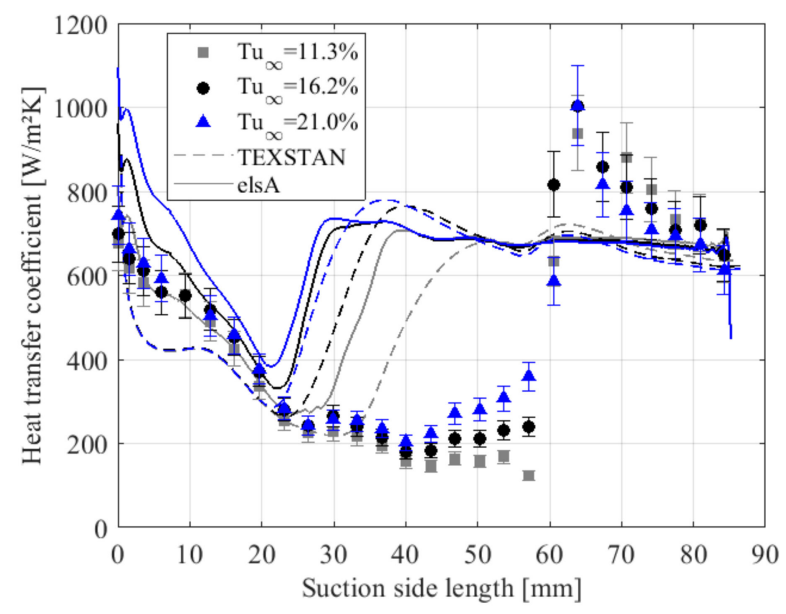

Figure 14. Suction side mean heat transfer coefficient distribution and TEXSTAN and elsA predictions (Case C: $M_{i s, \text { out }}=0.92, R e_{i s, o u t}=1.02 \times 10^{6}, T_{g} / T_{w}=1.36$ ).

Again, increase of the freestream turbulence, now above 16\%, does not lead to an earlier onset of transition due to the AG-S correlation formulation.

The very high heating seen in the experiments is not shown in the prediction for the turbulent boundary layer. Nevertheless, the code reaches the turbulent levels towards the trailing edge of the vane.

\section{Conclusions}

Heat transfer measurements were made on the high-pressure VKI LS89 vane under elevated levels of freestream turbulence. A novel grid was manufactured, generating turbulence intensities within 11-26\% and integral length scales between 1-2 cm. In the present paper, three test cases were studied, for a subsonic and two transonic Mach number distributions. Experimental results indicated that a considerable increase of freestream turbulence intensity resulted only in a moderate increase of the stagnation heat transfer coefficient. Changes in the boundary layer stability are found to be very dependent on the driving streamwise pressure gradients. Nevertheless, the turbulence increase led to earlier transition regions for a mild pressure gradient distribution. For transonic exit conditions, it resulted in a more upstream (acceleration dependent) transition onset and in the reduction of a separation bubble size.

A comparison with the RANS elsA and the Boundary Layer Code (BLC) TEXSTAN yielded reasonable results for the turbulent region of the boundary layer. Stagnation and early laminar heat transfer predictions at these levels of turbulence intensity require the use of a two-equation model instead of the mixing length one in TEXSTAN. The elsA code provided a better prediction for these regions, especially for the lowest turbulence case. An issue remains in the accurate prediction of the stagnation region at very high turbulence intensities as well as of the transition where the streamwise pressure gradients stabilizing effect is not completely accounted for. The high complexity of these test cases requires, as expected, more complex numerical approaches, such as LES or even DNS.

Author Contributions: The experimental and boundary layer code study was undertaken by T.S.C.F. and T.A. The numerical investigation by means of RANS was developed by E.C. The original draft of the paper was prepared by T.F. and all authors contributed to the production of the final manuscript and to the review and editing process.

Funding: This research was funded by Safran Tech.

Acknowledgments: The authors thankfully acknowledge the Mach number predictions from Riccardo Rubini, the availability of the boundary layer code from Mike Crawford and the financial support from Safran Tech.

Conflicts of Interest: The authors declare no conflict of interest. 


\section{Nomenclature}

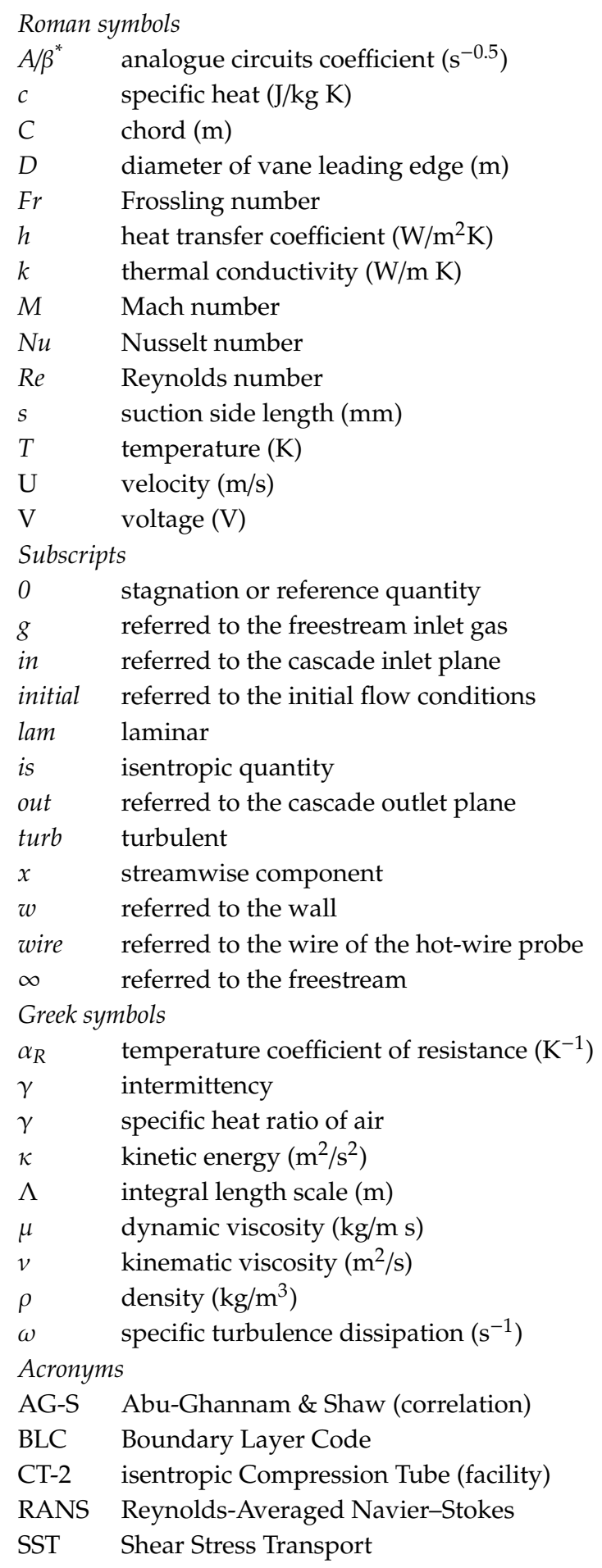

\section{References}

1. Denton, J.D. The 1993 IGTI Scholar Lecture: Loss Mechanisms in Turbomachines. J. Turbomach. 1993, 115, 621-656. [CrossRef]

2. Mayle, R.E. The 1991 IGTI Scholar Lecture: The role of laminar-turbulent transition in gas turbine engines. J. Turbomach. 1991, 113, 509-536. [CrossRef]

3. Goldstein, R.J.; Lau, K.Y.; Leung, C.C. Velocity and turbulence measurements in combustion systems. Exp. Fluids 1983, 1, 93-99. [CrossRef] 
4. Van Fossen, G.J.; Bunker, R.S. Augmentation of stagnation region heat transfer due to turbulence from a DLN can combustor. J. Turbomach. 2000, 123, 140-146. [CrossRef]

5. Van Fossen, G.J.; Bunker, R.S. Augmentation of stagnation region heat transfer due to turbulence from an advance dual-annular combustor. In Proceedings of the ASME Turbo Expo 2002: Power for Land, Sea and Air, Amsterdam, The Netherlands, 3-6 June 2002; ASME: New York, NY, USA, 2002.

6. Wang, H.P.; Goldstein, R.J.; Olson, S.J. Effect of high freestream turbulence with large length scale on blade heat/mass transfer. J. Turbomach. 1999, 121, 217-224. [CrossRef]

7. Brandt, L.; Schlatter, P.; Henningson, D.S. Transition in boundary layers' subject to free-stream turbulence. J. Fluid Mech. 2004, 517, 167-198. [CrossRef]

8. Van Fossen, G.J.; Simoneau, R.J.; Ching, C.Y. Influence of turbulence parameters, Reynolds number, and body shape on stagnation-region heat transfer. J. Heat Transf. 1995, 117, 597-603. [CrossRef]

9. Holmberg, D.G.; Diller, T.E. Simultaneous heat flux and velocity measurements in a transonic turbine cascade. J. Turbomach. 2005, 127, 502-506. [CrossRef]

10. Nix, A.C.; Smith, A.C.; Diller, T.E.; Ng, W.F.; Thole, K.A. High intensity, large length-scale freestream turbulence generation in a transonic turbine cascade. In Proceedings of the ASME Turbo Expo 2002: Power for Land, Sea and Air, Amsterdam, The Netherlands, 3-6 June 2002; ASME: New York, NY, USA, 2002.

11. Nix, A.C.; Diller, T.E.; Ng, W.F. Experimental measurements and modelling of the effects of large-scale freestream turbulence on heat transfer. J. Turbomach. 2007, 129, 542-550. [CrossRef]

12. Carullo, J.S.; Nasir, S.; Cress, R.D.; Ng, W.F.; Thole, K.A.; Zhanf, L.J.; Moon, H.K. The effects of freestream turbulence, turbulence length scale and exit Reynolds number on turbine blade heat transfer in a transonic cascade. J. Turbomach. 2011, 133, 011030. [CrossRef]

13. Arts, T.; Lambert de Rouvroit, M. Aero-thermal performance of a two dimensional highly loaded transonic turbine nozzle guide vane: A test case for inviscid and viscous flow computations. J. Turbomach. 1992, 114, 147-154. [CrossRef]

14. Steelant, J.; Dick, E. Modeling of laminar-turbulent transition for high freestream turbulence. J. Fluids Eng. 2001, 123, 22-30. [CrossRef]

15. Fransen, R.; Collado Morata, E.; Duchaine, F.; Gourdain, N.; Gicquel, L.Y.M.; Vial, L.; Bonneau, G. Comparison of RANS and LES in high pressure turbines. In Proceedings of the 3ème Colloque INCA, ONERA, Toulouse, France, 17-18 November 2011.

16. Gourdain, N.; Gicquel, L.Y.M.; Collado, E. Comparison of RANS and LES for prediction of wall heat transfer in a highly loaded turbine guide vane. J. Propuls. Power 2012, 28, 423-433. [CrossRef]

17. Collado Morata, E.; Gourdain, N.; Duchaine, F.; Gicquel, L.Y.M. Effects of freestream turbulence on high pressure turbine blade heat transfer predicted by structured and unstructured LES. Int. J. Heat Mass Transf. 2012, 55, 5754-5768. [CrossRef]

18. Rinaldi, E.; Raspopov, R.S.; Colonna, P.; Pecnik, R. Modeling curvature effects on turbulence transition for turbomachinery flows. In Proceedings of the ASME Turbo Expo 2014: Turbine Technical Conference and Exposition, Düsseldorf, Germany, 16-20 June 2014; ASME: New York, NY, USA, 2002.

19. Segui, L.M.; Gicquel, L.Y.M.; Duchaine, F.; de Laborderie, J. LES of the LS89 cascade: Influence of inflow turbulence on the flow prediction. In Proceedings of the 12th European Conference on Turbomachinery Fluid Dynamics and Thermodynamics, Euroturbo, Stockholm, Sweden, 3-7 April 2017.

20. Brunet, V.; Croner, E.; Minot, A.; de Laborderie, J.; Lippinois, E.; Stéphane Richard, S.; Boussuge, J.-F.; Dombard, J.; Duchaine, F.; Laurent Gicquel, L.; et al. Comparison of various CFD codes for LES simulations of turbomachinery: From inviscid vortex convection to multi-stage compressor. In Proceedings of the ASME Turbo Expo 2018: Turbomachinery Technical Conference and Exposition, Oslo, Norway, 11-15 June 2018; ASME: New York, NY, USA, 2002.

21. Pichler, R.; Sandberg, R.D.; Laskowski, G.; Michelassi, V. High-fidelity simulations of a linear HPT vane cascade subject to varying inlet turbulence. In Proceedings of the ASME Turbo Expo 2017: Turbomachinery Technical Conference and Exposition, Charlotte, NC, USA, 26-30 June 2017; ASME: New York, NY, USA, 2002.

22. Pichler, R.; Kopriva, J.; Laskowsi, G.; Michelassi, V.; Sandberg, R. Highly resolved LES of a linear HPT vane cascade using structured and unstructured codes. In Proceedings of the ASME Turbo Expo: Turbomachinery Technical Conference and Exposition, Seoul, Korea, 13-17 June 2016; ASME: New York, NY, USA, 2002. 
23. Seguí Troth, L.M. Multi-Physics Coupled Simulations of Gas Turbines. Ph.D. Thesis, Université de Toulouse, Toulouse, France, 2017.

24. Cação Ferreira, T.S.; Arts, T. Investigation of temperature influence in the production of higher turbulence. In Proceedings of the 9th International Symposium on Turbulence, Heat and Mass Transfer, International Centre for Heat and Mass Transfer, Rio de Janeiro, Brazil, 10-13 July 2018.

25. Schultz, D.L.; Jones, T.V.; Oldfield, M.L.G.; Daniels, L.C. A new transient cascade facility for the measurement of heat transfer rates. In Proceedings of the AGARD Conference no. 229-High Temperature Problems in Gas Turbine Engines, Advisory Group for Aerospace Research and Development, Ankara, Turkey, 19-23 September 1978.

26. Jones, T.V.; Schultz, D.L.; Hendley, A.D. On the Flow in an Isentropic Light Piston Tunnel; H.M. Stationery Office: London, England, 1973.

27. Fontaneto, F. Aero-Thermal Performance of a Film-Cooled High-Pressure Turbine Blade/Vane: A Test Case for Numerical Codes Validation. Ph.D. Thesis, von Karman Institute/Universitá degli Studi di Bergamo, Bergamo, Italy, 2014.

28. Cukurel, B.; Acarer, S.; Arts, T. A novel perspective to high speed cross-hot-wire calibration methodology. Exp. Fluids 2012, 53, 1073-1085. [CrossRef]

29. Moffat, R.J. Describing the uncertainties in experimental results. Exp. Therm. Fluid Sci. 1988, 1, 3-17. [CrossRef]

30. Moffat, R.J. Gas Temperature Measurement. Proceeding of temperature-Its Measurement and Control in Science and Industry. Appl. Methods Instrum. 1961, 3, 553-571.

31. Ligrani, P.M.; Camci, C.; Grady, M.S. Thin Film Heat Transfer Gage Construction and Measurement Details; VKI Internal Note 72; von Karman Institute for Fluid Dynamics: Rhode-Saint-Genèse, Belgium, 1982.

32. Richards, B.E. Heat transfer measurements related to hot turbine components in the von Karman Institute Hot Cascade Tunnel. In Proceedings of the AGARD Conference no. 281-Testing and Measurement Techniques in Heat Transfer and Combustion, Advisory Group for Aerospace Research and Development, Brussels, Belgium, 5-7 May 1980.

33. Consigny, H.; Richards, B.E. Short duration measurements of heat transfer rate to a gas turbine rotor blade. J. Eng. Power 1982, 104, 542-551. [CrossRef]

34. Schultz, D.L.; Jones, T.V. Heat Transfer Measurements in Short-Duration Hypersonic Facilities; AGARDograph no.165; Advisory Group for Aerospace Research and Development: Paris, France, 1973.

35. Oldfield, M.L.G.; Jones, T.V.; Schultz, D.L. Online computer for transient turbine cascade instrumentation. IEEE Trans. Aerosp. Electron. Syst. 1978, 14, 738-749. [CrossRef]

36. Camci, C. Experimental and Theoretical Study of Film Cooling On a Gas Turbine Blade. Ph.D. Thesis, von Karman Institute/Katholieke Universiteit Leuven, Leuven, Belgium, 1985.

37. Cação Ferreira, T.S.; Vasilakopoulos, N.; Arts, T. Investigation of thermal effect on bypass transition on a high-pressure turbine guide vane. J. Turbomach. 2019, 141, 051006. [CrossRef]

38. Arts, T.; Camci, C. Short Duration Heat Transfer Measurements; VKI LS 1985-03-Measurement Techniques in Turbomachines; von Karman Institute: Rhode-Saint-Genèse, Belgium, 1985.

39. Castro, I.; Haque, A. The structure of a shear layer bounding a separation region. Part 2: Effects of free-stream turbulence. J. Fluid Mech. 1988, 192, 577-595. [CrossRef]

40. Isomoto, K.; Honami, S. The effect of inlet turbulence intensity on the reattachment process over a backward-facing step. J. Fluids Eng. 1989, 111, 87-92. [CrossRef]

41. Chong, T.P.; Zhong, S. On the momentum and thermal structures of turbulent spots in a favorable pressure gradient. J. Turbomach. 2006, 128, 689-698. [CrossRef]

42. Roach, P.E. The generation of nearly isotropic turbulence by means of grids. Int. J. Heat Fluid Flow 1987, 8 , 82-92. [CrossRef]

43. Crawford, M.E. TEXSTAN. Available online: http://www.texstan.com/ (accessed on 2 May 2019).

44. Cambier, L.; Gazaix, M.; Heib, S.; Plot, S.; Poinot, M.; Veuillot, J.P.; Boussuge, J.F.; Montagnac, M. An overview of the multi-purpose elsA flow solver. J. Aerosp. Lab 2011, 2, 1-15.

45. Cambier, L.; Gazaix, M.; Heib, S.; Plot, S. The Onera elsA CFD software: Input from research and feedback from industry. Mech. Ind. 2013, 14, 159-174. [CrossRef] 
46. Menter, F.R. Two-equation eddy-viscosity turbulence models for engineering applications. AIAA J. 1994, 32, 1598-1605. [CrossRef]

47. Langtry, R. A Correlation-Based Transition Model Using Local Variables for Unstructured Parallelized CFD Codes. Ph.D. Thesis, Universität Stuttgart, Stuttgart, Germany, 2006.

(C) 2019 by the authors. Licensee MDPI, Basel, Switzerland. This article is an open access article distributed under the terms and conditions of the Creative Commons Attribution (CC BY-NC-ND) license (http://creativecommons.org/licenses/by-nc-nd/4.0/). 